13.1

\title{
Экспериментальное исследование процессов теплопереноса в тонкопленочных структурах на основе перовскитов методом низкокогерентной тандемной интерферометрии
}

\author{
(С) В.В. Травкин ${ }^{1,2}$, А.И. Коптяев ${ }^{2}$, Г.Л. Пахомов ${ }^{1,2}$, П.В. Волков ${ }^{1}$, Д.А. Семиков ${ }^{1,2}$, А.Ю. Лукьянов ${ }^{1}$ \\ ${ }^{1}$ Институт фризики микроструктур РАН, Нижний Новгород, Россия \\ ${ }^{2}$ Ивановский государственный химико-технологический университет, Иваново, Россия \\ E-mail: trav@ipmras.ru
}

Поступило в Редакцию 13 июля 2021 г.

В окончательной редакции 26 августа. 2021 г.

Принято к публикации 27 августа 2021 г.

Исследованы процессы теплообмена в системе прототип солнечного элемента/окружающая среда в режиме, близком к эксплуатационному. В качестве прототипа использовалась тонкопленочная структура на основе гибридного многокомпонентного иодоплюмбатного перовскита. Построена математическая модель температурного поля и рассчитаны тепловые карты элемента для разных уровней освещенности. Установлено, что при диффузной инсоляции разогрев структуры (максимум в районе полутолщины) не превышает критического для стабильности перовскитной фазы порога из-за диссипации в окружающую среду.

Ключевые слова: перовскиты, тонкие пленки, теплоперенос, солнечные элементы, диффузная инсоляция.

DOI: 10.21883/PJTF.2021.23.51781.18957

В настоящее время перовскитоподобные гибридные фотоабсорберы являются наиболее перспективными материалами для тонкопленочных солнечных элементов нового поколения, в том числе тандемной архитектуры [1], вследствие специфического сочетания оптоэлектронных свойств, технологичности и простоты изготовления. Однако такие фотоабсорберы недостаточно устойчивы к химической деградации, которую можно представить как фотолиз, пиролиз $[2,3]$ и электролиз [4] - побочные процессы, которые в режиме генерации электроэнергии на масштабах времени более нескольких сотен часов существенно влияют на КПД солнечного элемента. Ранее мы исследовали проблемы фотолиза и электролиза перовскитного слоя при 1) приложении постоянного электрического поля и 2) облучении в коротковолновой части видимого диапазона $[4,5]$. Но в литературе по-прежнему мало внимания уделяется вопросу, сопровождается ли поглощение света перовскитом повышением локальной температуры, которое также может приводить к деградации (пиролиз), или же тепло рассеивается внутри элемента [3]. Чередующиеся функциональные (фотоабсорбирующие, зарядотранспортные, буферные) слои с различной теплопроводностью - неорганические, например оксид молибдена $\left(\mathrm{MoO}_{3}\right), \varkappa=25 \mathrm{~W} /(\mathrm{m} \cdot \mathrm{K})[6]$, и молекулярные, например металлофталоцианин, $x<0.6 \mathrm{~W} /(\mathrm{m} \cdot \mathrm{K})$ [7], - могут влиять на эффективность теплоотведения с пленки перовскита на подложку. Следует отметить, что большое число интерфейсов, характерное для многослойного гибридного фотовольтаического преобразователя, является причиной значительных погрешностей при измерении температуры оптическими методами (например, с помощью пирометров) вследствие интерференционных эффектов. Обычные „контактные“ методы контроля температуры (термопара и т.п.) также непригодны для решения этой задачи в связи с измерением температуры самого датчика вместо конкретной рабочей области образца. Поэтому правильнее использовать бесконтактные оптические методы, среди которых низкокогерентная тандемная интерферометрия с нанометровым разрешением обеспечивает наиболее адекватную оценку температуры в многослойных тонкопленочных структурах даже в экстремальных условиях [8].

В настоящей работе с использованием комбинации вакуумных и жидкостных методов осаждения были получены многослойные тонкопленочные структуры вида стекло/легированный оксид олова (FTO)/ $\mathrm{MoO}_{3}(10 \mathrm{~nm}) /$ фталоцианин титанила $\mathrm{TiOPc}(25 \mathrm{~nm}) /$ гибридный трехкатионный иодоплюмбатный перовскит $\left(\mathrm{Cs}_{0.1} \mathrm{MA}_{0.8} \mathrm{BA}_{0.1}\right) \mathrm{PbI}_{3}(300 \mathrm{~nm}) / \mathrm{MoO}_{3}(10 \mathrm{~nm}) / \mathrm{TiOPc}(25 \mathrm{~nm}) /$ $\mathrm{MoO}_{3}(10 \mathrm{~nm})$. Такая схема была обусловлена необходимостью последующего изготовления прототипа тандемной конфигурации с двумя комплементарными фотоабсорберами, буферными и/или транспортными слоями. В качестве источника излучения использовалась ксеноновая дуговая лампа высокого давления с фильтром AM1.5G и фокусирующей линзой с диафрагмой. Подробное описание методик изготовления образцов можно найти в работах [5,9]. С помощью разработанной в ИФМ РАН оригинальной установки бесконтактного измерения температуры на базе тандемного низкокогерентного интерферометра (рис. 1) было проанализировано изменение реальной температуры образцов при непрерывном воздействии симулированного солнечного излучения различной длительности и интенсивности. Подробное описание методики измерения температуры 


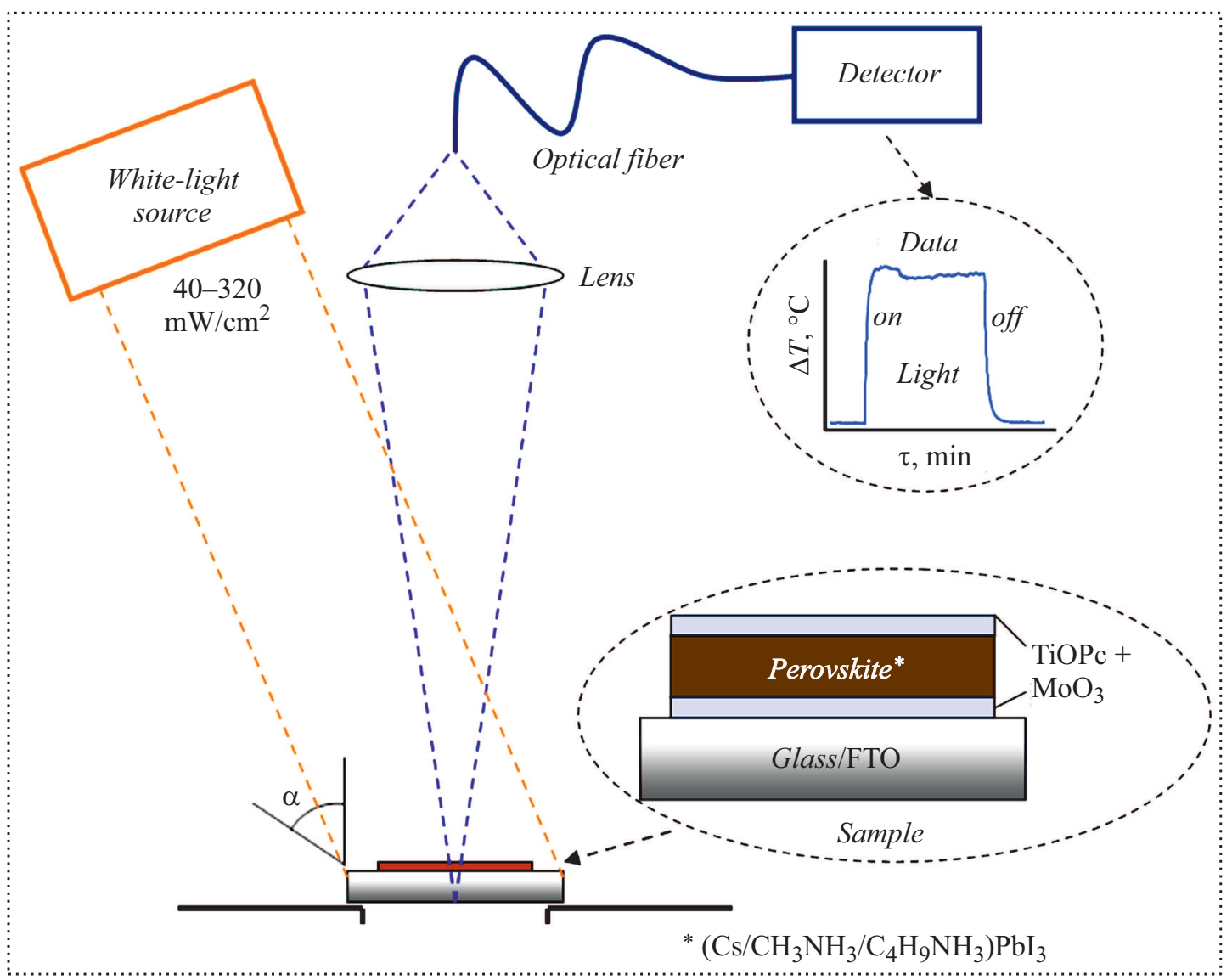

Pис. 1. Схема стенда бесконтактного контроля температуры тонкопленочных образцов.

можно найти в работе [8] и ссылках в ней. Численное моделирование процессов теплообмена в тонкопленочной структуре выполнялось в определенных граничных условиях: температуры окружающей среды, мощности падающего излучения, толщины и материала подложки. Вычисления проводились в системе Wolfram Mathematica методом конечных элементов с помощью алгоритмов Рунге-Кутты четвертого порядка. Вследствие большой разности размеров между переходными областями в слоях устройства, толщинами самих слоев и толщиной подложки были использованы сетки разных масштабов.

Исследуемые образцы размещались на бронзовом бруске, покрытом полированной черной алкидной эмалью, либо на подвесе из двух параллельных оптических волокон диаметром $250 \mu \mathrm{m}$. Тестировались два варианта: 1) стандартный солнечный элемент, сконструированный таким образом, чтобы поглощать максимальное количество падающего излучения; 2) полупрозрачный солнечный элемент с функционалом декорирующего энергогенерирующего покрытия. Мощность падающего излучения варьировалась в диапазоне $40-320 \mathrm{~mW} / \mathrm{cm}^{2}$ с целью моделирования различного уровня инсоляции. Одно солнце соответствует $\sim 100 \mathrm{~mW} / \mathrm{cm}^{2}$, в реальных условиях инсоляция определяется географическими координатами, метеорологиче- ской обстановкой и наличием солнечного концентратора в схеме фотопреобразователя.

При мощности облучения $40 \mathrm{~mW} / \mathrm{cm}^{2}$ чистая подложка стекло/FTO, размещенная на темной поверхности, нагревается на $15^{\circ} \mathrm{C}$, а подложка с многослойной тонкопленочной структурой (покрытием) - на $20^{\circ} \mathrm{C}$ (рис. 2,a) относительно температуры окружающей среды $\left(\sim 23^{\circ} \mathrm{C}\right)$. На подвесе из оптоволокна при аналогичной мощности облучения разница температур между образцом и окружающей средой не превышает $10^{\circ} \mathrm{C}$ в случаях наличия либо отсутствия покрытия.

При $100 \mathrm{~mW} / \mathrm{cm}^{2}$ на подвесе чистая подложка и подложка с покрытием нагреваются на 15 и $25^{\circ} \mathrm{C}$ соответственно. Интересно, что подложка, на поверхность которой осажден только слой ТіОРс толщиной $50 \mathrm{~nm}$, нагревается почти на $20^{\circ} \mathrm{C}$.

При $120 \mathrm{~mW} / \mathrm{cm}^{2}$ на темной поверхности (рис. 2,a) подложка с покрытием нагревалась на $40^{\circ} \mathrm{C}$.

При $320 \mathrm{~mW} / \mathrm{cm}^{2}$ на темной поверхности (рис. 2,a) подложка с покрытием нагревалась на рекордные $90^{\circ} \mathrm{C}$ относительно температуры окружающей среды $\left(\sim 23^{\circ} \mathrm{C}\right)$.

Теоретические расчеты изменения температуры образцов, выполненные в соответствующих граничных условиях, показали хорошее соответствие результатов 

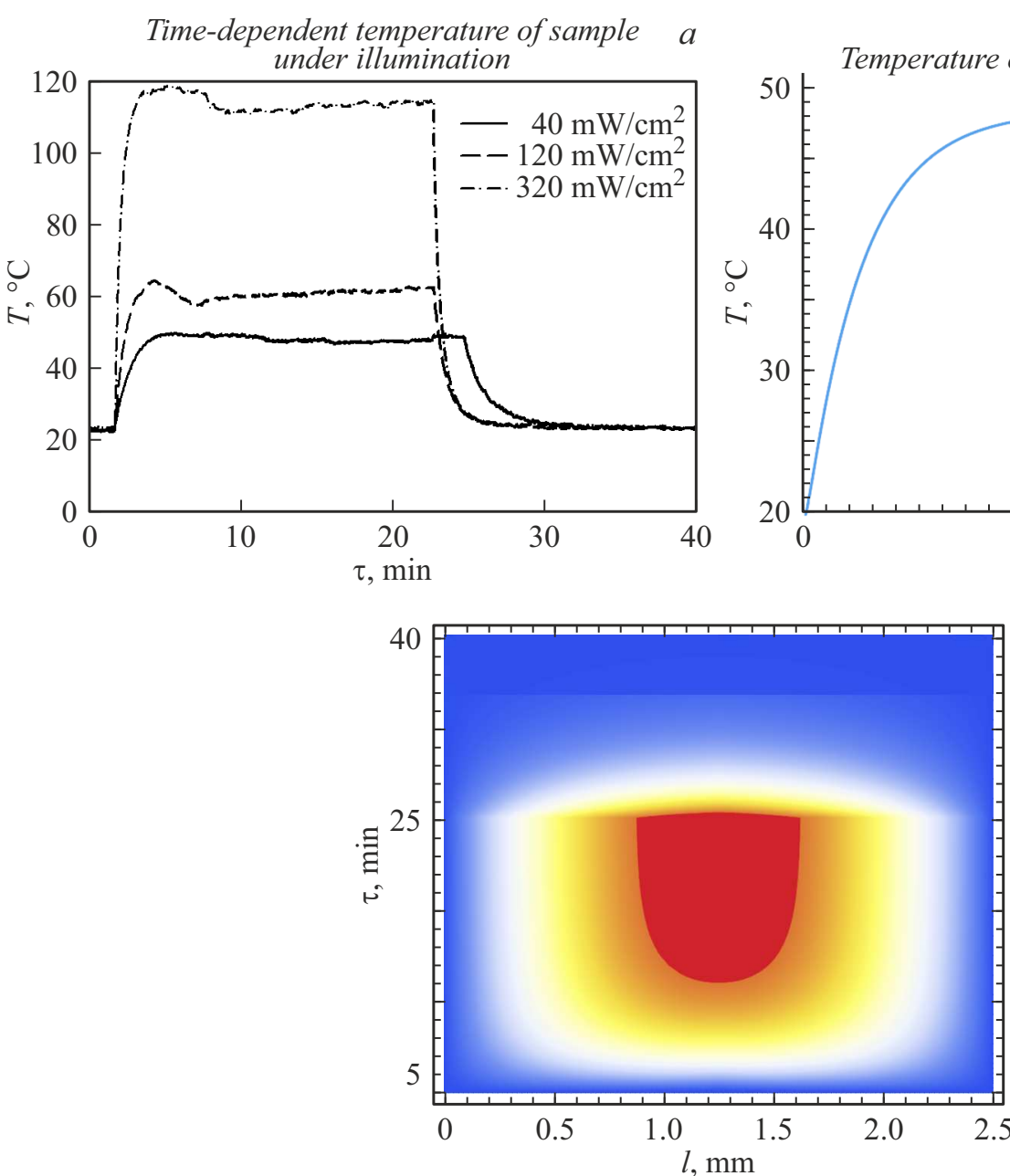

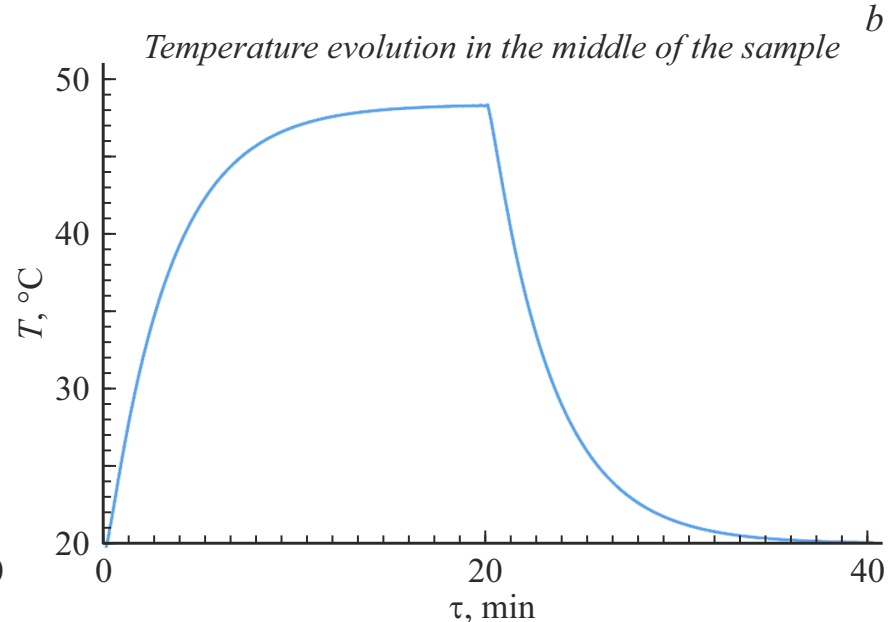

$c$
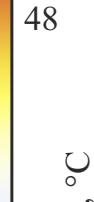

23

Рис. 2. Экспериментальные $(a)$ и расчетный $(b)$ профили изменения температуры тонкопленочной структуры на основе перовскита на подложке стекло/FTO при освещении симулированным солнечным излучением различной интенсивности. $c$ тепловая карта для расчетного профиля $(l=2.5 \mathrm{~mm}$ - толщина образца).

экспериментальным данным (рис. 2,b). Тепловая карта прототипа фотопреобразователя (рис. 2,c) показала, что тепловая энергия не аккумулируется в тонкопленочном покрытии, а быстро сбрасывается на подложку и затем медленно диссипирует в окружающую среду.

Таким образом, в условиях среднегодичной диффузной инсоляции, наблюдаемой на подавляющем большинстве территорий Российской Федерации, температура преобразователя не достигает критической (даже для иодоплюмбата метиламмония, $\mathrm{MAPbI}_{3}$ ) температуры в $75-80^{\circ} \mathrm{C}[10]$. А конструктивная/технологическая организация теплоотвода в элементе с целью минимизации пиролиза является проблемой второго порядка по отношению к проблемам фотолиза и электролиза перовскита.

\section{Финансирование работы}

Работа поддерживалась проектом ИФМ РАН ГЗ $0035-$ 2019-0024-С-01 в части разработки системы мониторинга температуры и проектом Российского фонда фун- даментальных исследований № 20-38-70123 в части получения тонкопленочных фотовольтаических структур на основе перовскитов и исследования процессов теплопереноса в них.

\section{Конфликт интересов}

Авторы заявляют, что у них нет конфликта интересов.

\section{Список литературы}

[1] N. Torabi, A. Behjat, Y. Zhou, P. Docampo, R.J. Stoddard, H.W. Hillhouse, T. Ameri, Mater. Today Energy, 12, 70 (2019). DOI: 10.1016/j.mtener.2018.12.009

[2] E.J. Juarez-Perez, Z. Hawash, S.R. Raga, L.K. Ono, Y.B. Qi, Energy Environ. Sci., 9 (11), 3406 (2016). DOI: 10.1039/C6EE02016J

[3] A.F. Akbulatov, M.I. Ustinova, G.V. Shilov, N.N. Dremova, I.S. Zhidkov, E.Z. Kurmaev, L.A. Frolova, A.F. Shestakov, S.M. Aldoshin, P.A. Troshin, J. Phys. Chem. Lett., 12 (18), 4362 (2021). DOI: 10.1021/acs.jpclett.1c00883 
[4] M.N. Drozdov, P.A. Yunin, V.V. Travkin, A.I. Koptyaev, G.L. Pakhomov, Adv. Mater. Interfaces, 6 (12), 1900364 (2019). DOI: 10.1002/admi.201900364

[5] V.V. Travkin, P.A. Yunin, A.N. Fedoseev, A.I. Okhapkin, Y.I. Sachkov, G.L. Pakhomov, Solid State Sci., 99, 106051 (2020). DOI: 10.1016/j.solidstatesciences.2019.106051

[6] Q. Xiao, C. Zhan, Y. You, L. Tong, R. Wei, X. Liu, Mater. Lett., 227, 33 (2018). DOI: 10.1016/j.matlet.2018.05.035

[7] O. Kamoun, A. Mami, M.A. Amara, R. Vidu, M. Amlouk, Micromachines, 10 (2), 138 (2019). DOI: $10.3390 / \mathrm{mi} 10020138$.

[8] P.V. Volkov, A.V. Goryunov, D.N. Lobanov, A.Y. Lukyanov, A.V. Novikov, A.D. Tertyshnik, M.V. Shaleev, D.V. Yurasov, J. Cryst. Growth, 448, 89 (2016). DOI: $10.1016 /$ j.jcrysgro.2016.05.029

[9] A.G. Boldyreva, I.S. Zhidkov, S. Tsarev, A.F. Akbulatov, M.M. Tepliakova, Y.S. Fedotov, S.I. Bredikhin, E.Y. Postnova, S.Y. Luchkin, E.Z. Kurmaev, K.J. Stevenson, P.A. Troshin, ACS Appl. Mater. Interfaces, 12 (16), 19161 (2020). DOI: $10.1021 /$ acsami.0c01027

[10] A. Kumar, U. Bansode, S. Ogale, A. Rahman, Nanotechnology, 31 (36), 365403 (2020).

DOI: $10.1088 / 1361-6528 / a b 97 d 4$ 